\title{
Biphasic allometric growth in juvenile green turtles Chelonia mydas
}

\author{
Michael Salmon ${ }^{1, *}$, Cody R. Mott ${ }^{2}$, Michael J. Bresette ${ }^{2}$ \\ ${ }^{1}$ Department of Biological Sciences, Florida Atlantic University, Boca Raton, Florida, 33431, USA \\ ${ }^{2}$ Inwater Research Group, Jensen Beach, Florida 34957, USA
}

\begin{abstract}
Green turtles raised in the laboratory widen faster than they lengthen, thus changing in shape from the proportions they show as hatchlings. By doing so, young turtles may sooner achieve a size refuge from their gape-limited predators. In this study, we document that wild juveniles captured at open-water weed lines in the Gulf of Mexico show similarly wider proportions, demonstrating for the first time that this growth pattern occurs in nature. We additionally quantified the shell dimensions of older juveniles that had abandoned weed lines and returned to occupy shallow coastal reefs. Those turtles exhibited a narrower 'hatchling like' body shape. We conclude that juvenile green turtles show a biphasic pattern of initial widening, followed later by a secondary narrowing once they achieve a size that exceeds $25-30 \mathrm{~cm}$ in straight-line carapace length. We hypothesize that secondary narrowing may be advantageous for reducing lethal interactions with a different subset of larger predators, those that typically dismember their prey rather than swallow them whole. Finally, we categorize this complex growth pattern as one of several vulnerability traits that promote juvenile turtle survival, and document that they are expressed in different combinations among other marine turtle species.
\end{abstract}

KEY WORDS: Allometric growth $\cdot$ Evolution $\cdot$ Predator-prey $\cdot$ Sea turtle $\cdot$ Vulnerability traits

\section{INTRODUCTION}

All marine turtle species are unusually fecund for reptiles, necessitated by high nest and juvenile mortality (Hendrickson 1980, Bolten 2003, Heithaus 2013). These circumstances select for females that invest little in each hatchling but instead invest in large clutches, deposited several times during any one breeding season (van Buskirk \& Crowder 1994). In that respect, sea turtle reproduction resembles the pattern shown by many $r$-selected marine organisms.

Population models for marine turtles predict that juvenile mortality rates decline with growth (Bolten 2003, Heppell et al. 2003). The reasons are difficult to determine because hatchlings and juveniles disperse widely either to continental shelf (flatbacks Natator depressus) or deeper offshore oceanic habitats (all

${ }^{*}$ Corresponding author: salmon@fau.edu other species; Bolten 2003), where their growth patterns, behavioral survival strategies, and interactions with predators are difficult and logistically challenging to study. Green turtle Chelonia mydas hatchlings, for example, exit the nest, crawl to the surf zone, swim offshore for several days, and then forage in association with oceanic weed lines (Witherington et al. 2012) before returning, on average after a 3-year 'oceanic' phase, to coastal (neritic) habitats (Bolten 2003, Avens \& Snover 2013). Hatchlings reared for several months provide insights into their early growth patterns; the turtles widen faster than they lengthen, which results in an elliptically shaped juvenile (Salmon \& Scholl 2014). Doing so may enhance survival by shortening the time required for small turtles to reach a refuge width from their gapelimited predators.

() The authors 2018. Open Access under Creative Commons by Attribution Licence. Use, distribution and reproduction are unrestricted. Authors and original publication must be credited. 
This study was inspired by the appearance of older green turtles, captured after they had completed the oceanic phase of development and returned to coastal habitats. These turtles showed dimensions that more closely resembled hatchling proportions than younger elliptical juveniles. Those observations led to the 3 questions we consider in this study. (1) When during ontogeny do older green turtle juveniles adopt a secondary growth trajectory that leads to the 're-narrowing' of their shape? (2) What might be the survival benefit(s) of such a complex growth pattern? (3) How do these morphological changes associated with growth in green turtles compare with other functional traits (characteristics affecting predator-prey interactions; Schmitz 2017) shown by marine turtles species during comparable periods of their development?

\section{MATERIALS AND METHODS}

\section{Laboratory-reared turtles}

Ten hatchlings were collected from each of 12 green turtle nests (6 nests in 2011; 6 nests in 2012; $\mathrm{n}=120$ hatchlings) that completed incubation on the beaches of Boca Raton, Florida, USA $\left(26.22^{\circ} \mathrm{N}\right.$, $80.07^{\circ} \mathrm{W}$ ). Turtles were maintained at Florida Atlantic University's (FAU) marine laboratory at the Gumbo Limbo Nature Complex for 12-14 wk, where they were individually housed in flow-through plastic containers, floating in seawater-filled tanks. Husbandry details are provided in Salmon \& Scholl (2014).

We marked each hatchling with non-toxic nail polish for nest identification. As hatchlings, and at $1 \mathrm{wk}$ intervals thereafter, their straight-line carapace length (SCL; notch to tip), straight-line carapace width (SCW), and mass (g) were measured using vernier calipers accurate to $0.1 \mathrm{~mm}$. At a mass of approximately $150 \mathrm{~g}$, the turtles were transported by boat about $20 \mathrm{~km}$ offshore and released in the Gulf Stream Current.

\section{Wild-caught turtles}

Larger juvenile turtles, captured in the wild, were obtained from in-water sites. These included deeper offshore habitats in the Gulf of Mexico, the shallow reefs adjacent to the East Coast of Florida, and the seawater intake canal (cooling water) of a nuclear power plant.
Gulf of Mexico turtles

The pelagic Sargassum seaweed habitat in the northern Gulf of Mexico was surveyed for neonate turtles as part of 2 projects, both undertaken to evaluate the impact of the 2010 Deepwater Horizon oil spill. The first project (Natural Resource Damage Assessment) was initiated between May and September 2011. The second project was completed over a span of several years (between May 2013 and July 2017). During both projects turtles were located from a boat and captured using a dip net. We held turtles briefly to obtain basic measurements (SCL and SCW) and then released them at the capture site. Capture sites ranged from $90.00^{\circ} \mathrm{W}(\sim 75 \mathrm{~km}$ west of Venice, Louisiana, USA) to $87.20^{\circ} \mathrm{W}$ (Pensacola, Florida, USA) longitude, and from $29.70^{\circ} \mathrm{N}(\sim 80 \mathrm{~km}$ south of Pensacola, Florida, USA) to $28.0^{\circ} \mathrm{N}(\sim 100 \mathrm{~km}$ south of Venice, Louisiana, USA) latitude.

\section{Nearshore reef turtles}

Divers, working at night, captured juvenile green turtles as they swam over or rested within shallow (2-6 $\mathrm{m}$ deep) near-shore reefs in Palm Beach County, Florida. Two reefs were used: the Breakers Reef $\left(26.70^{\circ} \mathrm{N}, 80.03^{\circ} \mathrm{W}\right)$ and the Boca Raton Reef $\left(26.32^{\circ} \mathrm{N}, 80.07^{\circ} \mathrm{W}\right)$, between May and October 2009. See Mott \& Salmon (2011) for further details.

\section{Power plant turtles}

The St. Lucie Power Plant, located on Florida's East Coast $\left(27.20^{\circ} \mathrm{N}, 80.14^{\circ} \mathrm{W}\right)$, draws in cooling water from the Atlantic Ocean through 3 large pipes (3.9-4.9 $\mathrm{m}$ diameter) that extend approximately $300 \mathrm{~m}$ offshore. Juvenile turtles often enter the intake pipes and are entrained into the $1500 \mathrm{~m}$ long intake canal that transports the cooling water to the power plant. A net, spanning the width of the canal, prevents the turtles from entering the power plant itself. Inwater Research biologists oversee the safe capture and removal of these turtles from the canal, typically within $24-72 \mathrm{~h}$ of entrainment, and provide for their safe return to coastal waters. We used data obtained from a normal sample of these turtles (no shark bite injuries or scute growth abnormalities) captured between 2012 and 2016. 


\section{Changes in body shape}

Body shapes of juvenile green turtles were analyzed by comparing their carapace proportions (length vs. width) to those shown by hatchlings. We used procedures described elsewhere (Salmon \& Scholl 2014), briefly summarized here. We measured the SCL and SCW of the hatchlings captured each year and used them to determine a hatchling ratio (SCW divided by SCL). This ratio was $<1$, as hatchlings are always longer than they are wide. The SCL of each laboratory-raised or wild-captured turtle was then multiplied by the hatchling ratio. The product was the expected SCW (expSCW), assuming that growing turtles retained their hatchling (SCW:SCL) proportions. The observed SCW (obsSCW) was the value actually measured from the same turtle, repeatedly as it grew.

These measurements were made once weekly and then averaged for the 10 turtles from each nest until they reached an SCL of $10-11 \mathrm{~cm}$. At that size, they were taken offshore and released.

We compared differences between the expected and observed SCW statistically using a 1-sample (repeated measures) $t$-test (Zar 1999) to determine if the observed and expected sample means came from the same population. If these comparisons revealed no statistically significant differences, we concluded that hatchling proportions were currently maintained by the juvenile turtles. If, however, differences between the 2 means were significant (at $\mathrm{p} \leq 0.05$ ), then we concluded that juvenile body shape proportions had changed from a hatchling shape as a consequence of allometric growth.

\section{RESULTS}

\section{Hatchling measurements}

The 60 hatchlings measured in 2011 averaged $51.0 \mathrm{~mm}$ in SCL and $39.1 \mathrm{~mm}$ in SCW. The 60 hatchlings measured in 2012 averaged $49.0 \mathrm{~mm}$ in SCL and $38.0 \mathrm{~mm}$ in SCW. The hatchling ratios for the 2 samples $(0.77,0.78)$ did not differ statistically $(t=$ $0.70, p=0.50$ ) and were pooled to yield a ratio of 0.78 .

\section{Laboratory-reared turtles}

We reared hatchlings until they grew to an SCL of just under $11 \mathrm{~cm}$. Those reared in 2011 took an average of 12.7 wk ( $\mathrm{n}=76$ weekly measurements on 6 nests) to reach $11 \mathrm{~cm} \mathrm{SCL}$, whereas those reared in 2012 grew slightly faster, requiring $12.3 \mathrm{wk}(\mathrm{n}=74$ weekly measurements on 6 additional nests) to reach this length. Both groups widened faster than they increased in length (Fig. 1). As a consequence, their mean $( \pm \mathrm{SD})$ observed SCW was significantly greater than their mean expected SCW $\left(\right.$ obsSCW $_{2011}=8.3 \pm$ $2.5, \quad \operatorname{expSCW} 2011=7.9 \pm 2.4, t=2.6, \mathrm{p}<0.01$; obsSCW $_{2012}=8.5 \pm 2.3, \operatorname{expSCW}_{2012}=8.1 \pm 2.3, t=$ $3.35, \mathrm{p}<0.001)$.

\section{Gulf of Mexico green turtles}

We captured 86 turtles that ranged between 13.3 and $26.9 \mathrm{~cm}$ in SCL (Fig. 2). Their mean observed SCW was significantly greater than their mean

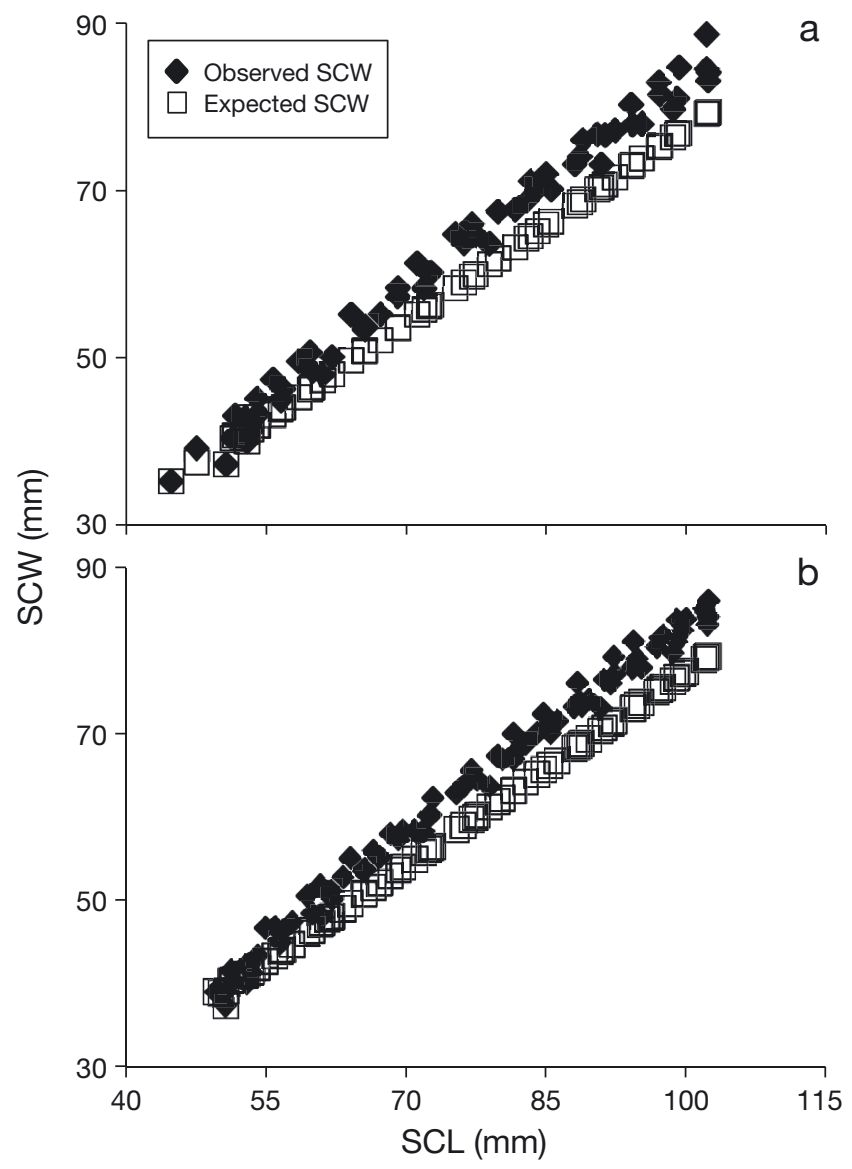

Fig. 1. The observed and expected straight-line carapace width (SCW) for 60 laboratory-reared green turtles, (a) 10 hatchlings per nest from 6 nests in 2011, and (b) 10 hatchlings from 6 nests in 2012, as they grew up to $110 \mathrm{~mm}$ in straight-line carapace length (SCL). Data points are the weekly averages of growth at each nest over a total of 12.7 wk in 2011 and $12.3 \mathrm{wk}$ in 2012. (Parts of these data have been previously published in Salmon \& Scholl [2014] and Salmon et al. [2016]) 


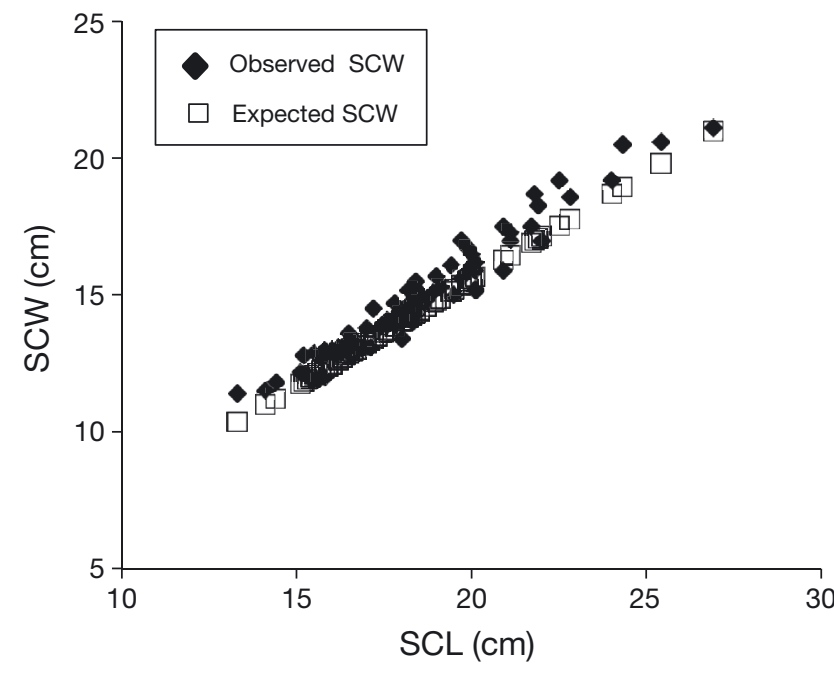

Fig. 2. Observed and expected straight-line carapace width (SCW) for the Gulf of Mexico green turtles $(\mathrm{n}=86)$ captured in the Sargassum weed line habitat. Note the change from a $\mathrm{mm}$ to a $\mathrm{cm}$ scale in both axes

expected SCW $($ obsSCW $=15.0 \pm 2.4, \operatorname{expSCW}=14.4$ $\pm 2.8, t=2.35, \mathrm{p}<0.02)$.

\section{Nearshore reef and power plant green turtles}

We captured 42 turtles at the nearshore reef that ranged in size between 26.0 and $59.0 \mathrm{~cm}$ in $\mathrm{SCL}$, and 99 turtles from the power plant cooling canal that measured 26.0-64.0 cm in SCL (Fig. 3). There were no statistical differences between their observed and expected SCW (nearshore reef: obsSCW $=28.7 \pm 7.1$, $\operatorname{expSCW}=28.1 \pm 7.1, t=0.55, \mathrm{p}=0.29$; power plant: obsSCW $=32.5 \pm 9.1 ; \operatorname{expSCW}=31.6 \pm 9.1, t=0.93$, $\mathrm{p}=0.18)$.

\section{DISCUSSION}

Our data show that after initially widening faster than they lengthen, green turtles revert to a shape that more closely resembles their appearance as hatchlings (Fig. 4). This secondary reversal in shape occurs at about the time when older juveniles shift from their oceanic phase to the occupancy of neritic coastal habitats (Bolten 2003).

An initial widening during early growth has also been documented in 4 other marine turtle species: loggerheads Caretta caretta and Kemp's ridley Lepidochelys kempii (Salmon et al. 2015); flatbacks Natator depressus (Salmon et al. 2016); leatherbacks Dermochelys coriacea (Pate \& Salmon 2017). How-

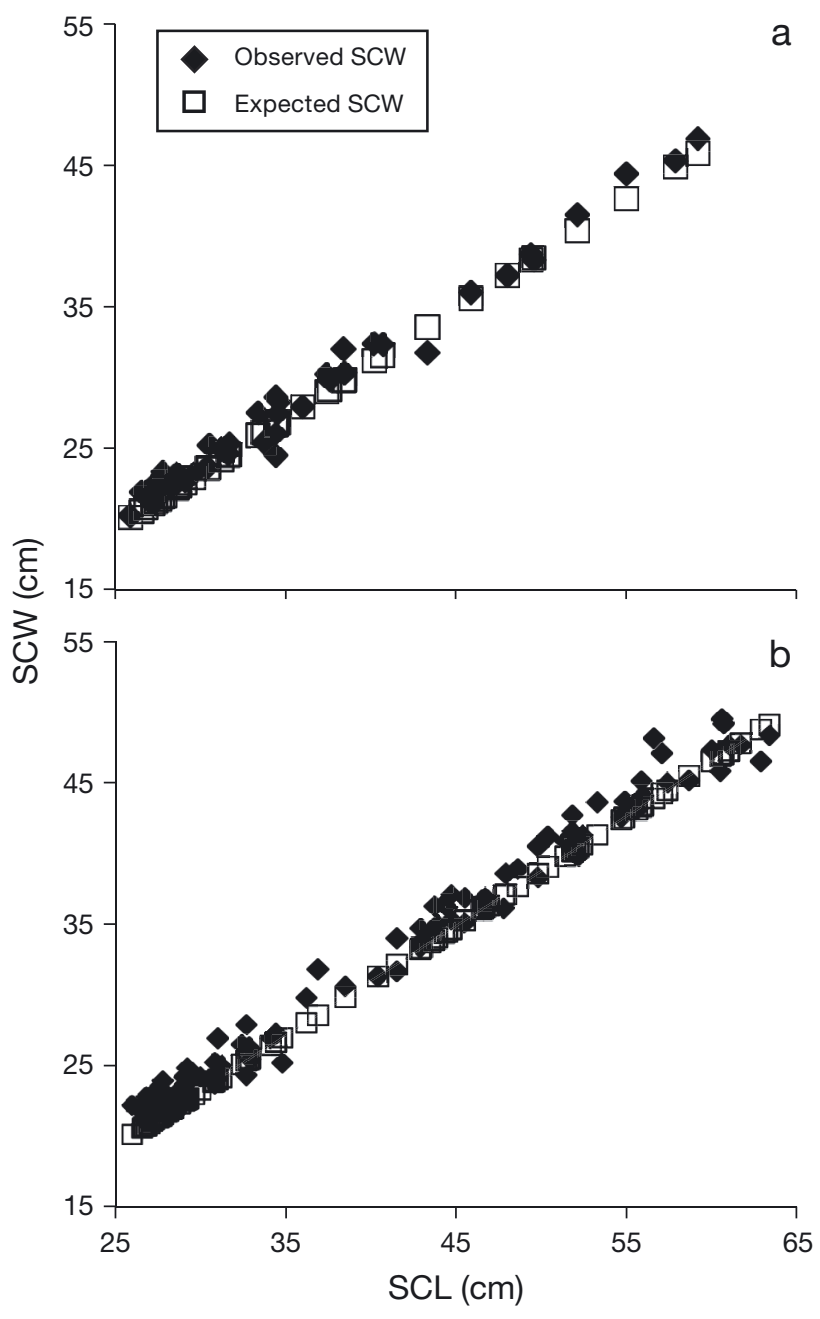

Fig. 3. Observed and expected straight-line carapace width (SCW) for (a) the nearshore reef $(\mathrm{n}=42)$ and $(\mathrm{b})$ power plant $(\mathrm{n}=99)$ green turtles

ever, all these measurements stemmed from laboratory-reared turtles. Their rearing conditions might have induced growth artifacts that could include abnormal changes in body shape. Our data from wild turtles captured in the Gulf of Mexico render this possibility unlikely, as these green turtles also possessed bodies that were proportionally wider than those of conspecific hatchlings.

Our new green turtle data, which included juveniles up to $65 \mathrm{~cm}$ in $\mathrm{SCL}$, support the hypothesis that during their early growth the turtles initially widen but later secondarily narrow, presumably through negative allometric growth. What remains unexplained is why such a complex pattern of growth should occur, what selection pressures promote it, and in what way such a reversal in morphology might be advantageous. 


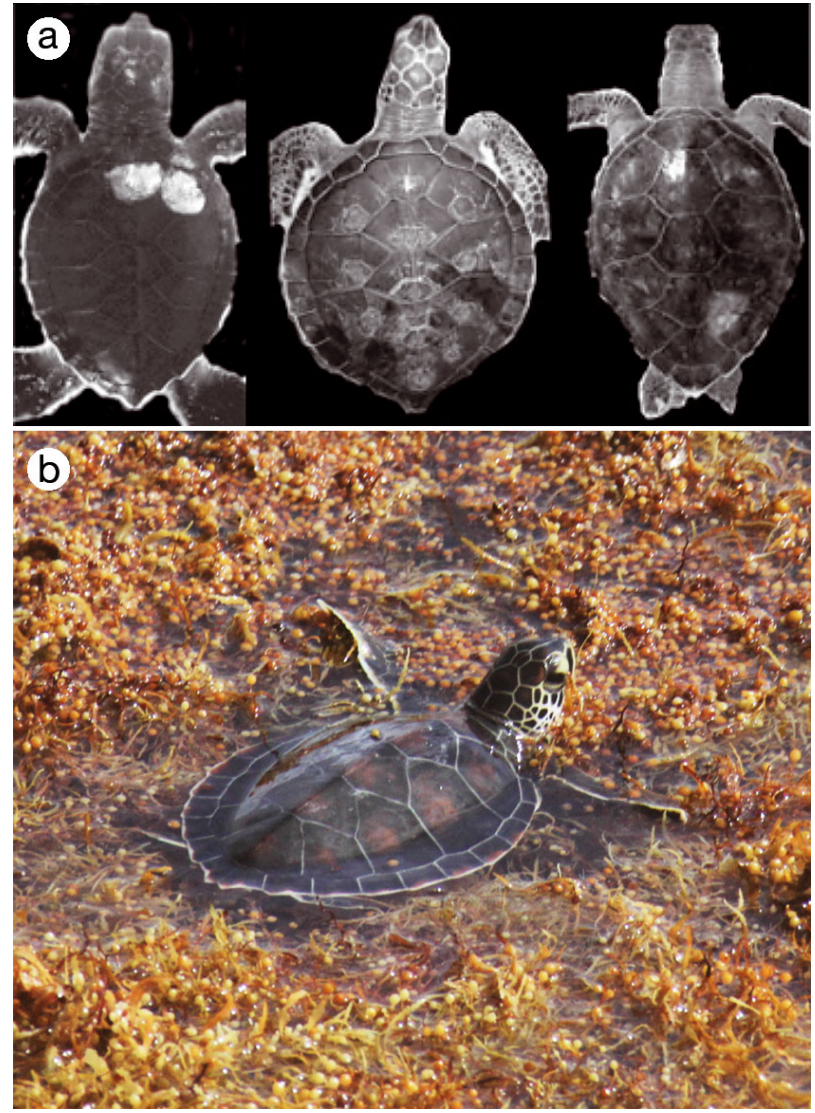

Fig. 4. (a) Green turtle body shapes during early development. Left, a hatchling at $4.9 \mathrm{~cm}$ in straight-line carapace length (SCL) (pigment marks are for nest identification); middle, a laboratory-raised juvenile at $10.5 \mathrm{~cm} \mathrm{SCL}$; right, a wild-caught juvenile at $35.0 \mathrm{~cm}$ SCL. (b) A wide-bodied juvenile, estimated at $9.0 \mathrm{~cm}$ in SCL, photographed while resting on Sargassum in the Gulf of Mexico (photo: M. Bresette)

\section{Hypotheses}

Body widening, followed by body narrowing, is a conspicuous element of early growth not only in green turtles but also in loggerheads (Kamezaki \& Matsui 1997). In both species, these changes occur when the turtles are young and especially vulnerable to predators (Hendrickson 1980, Heppell et al. 2003, Heithaus 2013), suggesting that changes in shape accompanying growth might have anti-predator, and therefore survival, benefits. Salmon \& Scholl (2014) hypothesized that carapace widening during the initial stages of growth might enable a small turtle to achieve a refuge size (proportions that exceed the gape of its predators) more rapidly than a turtle that grew isometrically, retaining its hatchling shape. Why, then, should a somewhat older juvenile turtle narrow its shape once again? We suggest 2 non- exclusive hypotheses that might represent plausible explanations.

One hypothesis is that as a turtle approaches a refuge size from all but the largest of its gape-limited predators (e.g. tunas and mahi-mahi Coryphaena hippurus), those benefits decline. At the same time, a further increase in prey size makes each turtle more profitable (and therefore, more attractive) to larger predators (e.g. sharks; Heithaus et al. 2002, 2008) that subdue prey by injurious attacks that can result in consumption of portions, or the entirety, of a turtle. We hypothesize that selection might then favor an alternative growth strategy, one that emphasizes the allocation of reserves to increases in length as a mechanism for promoting the appearance of a larger turtle. Such a change might also enhance growth rates to a larger size as wide-bodied juveniles initially lengthen and grow into a shape characteristic of older juveniles. In many species, older and larger juveniles are better able to defend against predators (Werner \& Gilliam 1984, McCoy et al. 2011, Nakazawa 2017).

A second possibility is that as the turtles grow larger and become more powerful, faster swimmers, drag forces increase (Vogel 1983, Schmidt-Nielsen 1984) and may compromise swimming speed and maneuverability. Adopting a proportionally narrower and more fusiform body shape reduces both pressure and frictional drag forces (Hildebrand 1974). Streamlined shapes are characteristic of hatchling sea turtles (Wyneken 1997) as well as other large animals that move through a viscous medium, especially those that, like all marine turtles, are migratory and travel long distances in search of feeding or breeding grounds (e.g. fishes, Webb 1984; marine mammals, Fish et al. 2008). For growing juvenile turtles, the energy savings associated with a more streamlined shape could be used to enhance growth rates and increase swimming power, speed and maneuverability, all essential elements associated with the biomechanics of escape (Lima \& Dill 1990, Heithaus et al. 2002, Moore \& Biewener 2015).

\section{Shape changes and other functional traits}

Functional traits are defined as any morphological, behavioral, psychological, or physiological characteristic affecting predator-prey interactions (Schmitz et al. 2015). Functional traits for predators ('foraging' or 'trophic' traits) determine their ability to capture prey. Functional traits for prey ('vulnerability' traits), such as the juvenile green turtles described in this study, promote their ability to avoid detection by, or 
to escape from, their predators and thus increase survival probabilities. These traits include body size (length, mass; McCoy et al. 2011), physical defenses (armoring, spination; Morgan 1989, Inbar \& LevYadun 2005), ability to avoid detection (crypsis or camouflage; Smith \& Salmon 2009), locomotor performance (Herrel \& Gibb 2006), categories of evasive or escape behavior (Higham et al. 2016), and the effects of predator-induced fear on prey behavior (Laundré et al. 2001, Heithaus et al. 2008).

We hypothesize that the shape changes we describe for green turtles represent one of several vulnerability traits displayed by marine turtles during early growth. We document others (Fig. 5) that vary in their expression but show similarities among related species. For example, carapace widening occurs in all sea turtle species, except the hawksbill Eretmochelys imbricata, which has a narrower body that may fit more easily under reef ledges or into reef crevasses (Salmon et al. 2018). Carapace widening is weakly (but significantly) developed in leatherbacks (Pate \& Salmon 2017) and is more pronounced in young flatbacks than in young green turtles (Salmon et al. 2016). It is most strongly expressed in juvenile Kemp's ridley turtles that, from an early age, possess shells that are as wide as they are long (Salmon et al. 2015), a condition that uniquely persists even in adults (Pritchard 2007).

Avoiding detection through behavior is also a common functional trait, because small sea turtles are defenseless during the earliest stages of growth (Heithaus 2013). Once again, expression varies and falls into 3 categories: hiding in flotsam (hawksbills, log- gerheads, Kemp's ridleys, green turtles; Carr 1986, 1987), hiding in turbid water (flatbacks; Salmon et al. 2016), and ignoring predators (leatherbacks; Salmon et al. 2004, Pate \& Salmon 2017; see Fig. 5), with the last category the least studied or understood.

As hatchlings and post-hatchlings, turtles such as hawksbills, loggerheads, and Kemp's ridleys hide in flotsam. These species are closely related (NaroMaciel et al. 2008) and apparently have converged on a common behavioral strategy: masquerade (resemblance to an inedible background; Smith \& Salmon 2009) as a primary defense for avoiding detection. They couple this defense with armoring (imbrication and spination in hawksbills, spination and carapace widening in the other species). When hawksbills, loggerheads, and Kemp's ridleys are threatened, their secondary defense is to freeze in a tuck position (Witherington 2002, Witherington et al. 2012). This combination of traits is consistent with their relatively modest swimming and diving capabilities (Wyneken 1997).

Green turtles and flatbacks, which are more closely related to one another than to other species of marine turtles (Naro-Maciel et al. 2008), have converged on a different set of vulnerability trait characters. These emphasize a streamlined shape, smooth shell, high aspect ratio flippers, and impressive locomotor skills even at an early age. Both species, and especially flatbacks, are capable of rapid speed bursts during either horizontal swimming or vertical diving (Wyneken 1997, Salmon et al. 2004, 2010). They likely use those capabilities as a secondary response toward impending threats, with detection avoidance being their primary defense. Small green turtles hide by burrowing into Sargassum mats (anachoresis, hiding by using objects to obscure their appearance; Smith \& Salmon 2009). Throughout their early ontogeny, flatbacks select turbid coastal shelf waters as nursery areas in Australia and New Guinea (Walker \& Parmenter 1990). Turbidity may reduce probabilities of detection (Walker 1991). Flatbacks also replenish their oxygen supply quickly (Salmon et al. 2010), presumably to avoid sea eagles Haliaeetus leucogaster that capture them when the turtles surface to breathe (Walker \& Parmenter 1990). Hatchling flatbacks also possess an unusual pattern of carapace coloration, one that disrupts their
Fig. 5. Distribution by species of 5 vulnerability traits found in post-hatchling marine turtles. Masquerade is resemblance (in this instance) to a non-edible object; anachoresis is the use of objects to hide one's appearance (Endler 1986). Abbreviations: Ei, hawksbill; Cc, loggerheads; Lk, Kemp's ridley; Cm, green turtle; Nd, flatback; Dc, leatherback. See 'Discussion: Shape changes and other functional traits' for further explanation 
body outline by creating false inside edges. Over a period of several weeks, as the turtles grow, this disruptive color pattern gradually morphs into a uniformly dark carapace (Salmon et al. 2016). This change occurs just before the turtles become too large for sea eagles to transport back to their nest for consumption, but as they become more attractive prey to larger underwater predators. Thus, both green turtles (using body shape) and flatbacks (using body color) show ontogenetic changes in morphology that may anticipate shifts in the kinds of predators they will encounter at a larger size.

In conclusion, we determined that during an initial period of juvenile growth, both laboratory-reared and wild-caught green turtles widened faster than they lengthened. This pattern subsequently reverses such that older juveniles revert to a shape that more closely resembles their appearance as hatchlings. The secondary shape reversal occurs close to the time when older juveniles shift from oceanic to coastal habitats. We hypothesize that this complex pattern of shape change is a functional trait that enhances survival probabilities as the turtles grow and become more profitable to a different array of predators. It thus appears that there is surprising flexibility in the development of the shell, perhaps a necessity as this structure must provide some measure of protection to a small turtle that faces many threats to its survival. At the same time, however, sea turtles must also retain a shape that enables rapid and efficient locomotion in a viscous medium. Biphasic allometric growth may be a response to these conflicting demands.

Acknowledgements. This research was supported by the National Save the Sea Turtle Foundation, the US Fish and Wildlife Service, the National Marine Fisheries Service, the University of Central Florida Marine Turtle Research Group, the Florida Power and Light Company, an anonymous donor, and by personal funds. We thank the St. Lucie Power Plant's Land Utilization Department, specifically V. Munne, for the continued support of sea turtle research at the site. Critical readings by J. Wyneken, M. J. Saunders, E. Seney, J. Senko and 3 anonymous referees improved manuscript clarity and organization. Gulf of Mexico turtles were captured and released at Sargassum weed line habitats in compliance with permits from the National Marine Fisheries Service (NMFS 21169). Nearshore reef turtles were captured under authorizations provided by the State of Florida (Marine Turtle Permit 173) and a NMFS permit (13573). Power Plant turtles were captured under authorizations provided by the State of Florida (Marine Turtle Permit 125) and NMFS (Endangered Species Act, Section 7, Biological Opinion). Authorization for rearing turtles at the FAU Marine Laboratory was permitted by the State of Florida (Marine Turtle Permit 073) and the FAU Institutional Animal Care and Use Committee (Protocol A13-27).

\section{LITERATURE CITED}

Avens L, Snover ML (2013) Age and age estimation in sea turtles. In: Wyneken J, Lohmann KJ, Musick JA (eds) The biology of sea turtles, Vol 3. CRC Press, Boca Raton, FL, p 97-133

Bolten AB (2003) Variation in sea turtle life history patterns: neritic vs. oceanic developmental stages. In: Lutz PL, Musick JA, Wyneken J (eds) The biology of sea turtles, Vol 2. CRC Press, Boca Raton, FL, p 243-258

Carr A (1986) Rips, FADS, and little loggerheads. Bioscience 36:92-100

Carr A (1987) New perspectives on the pelagic stage of sea turtle development. Conserv Biol 1:103-121

Endler JA (1986) Defense against predators. In: Feder ME, Lauder GV (eds) Predator-prey relationships: perspective and approaches from the study of lower vertebrates. University of Chicago Press, Chicago, p 109-134

Fish FE, Howle LE, Murray MM (2008) Hydrodynamic flow control in marine mammals. Integr Comp Biol 48: 788-800

Heithaus MR (2013) Predators, prey, and the ecological roles of sea turtles. In: Wyneken J, Lohmann KJ, Musick JA (eds) The biology of sea turtles, Vol 3. CRC Press, Boca Raton, FL, p 249-284

*Heithaus M, Frid A, Dill L (2002) Shark-inflicted injury frequencies, escape ability, and habitat use of green and loggerhead turtles. Mar Biol 140:229-236

* Heithaus MR, Wirsing AJ, Thomson JA, Burkholder DA (2008) A review of lethal and non-lethal effects of predators on adult marine turtles. J Exp Mar Biol Ecol 356: 43-51

Hendrickson JR (1980) The ecological strategies of sea turtles. Am Zool 20:597-608

Heppell SS, Snover ML, Crowder LB (2003) Sea turtle population ecology. In: Lutz PL, Musick JA, Wyneken J (eds) The biology of sea turtles, Vol 2. CRC Press, Boca Raton, FL, p 275-306

*Herrel A, Gibb AC (2006) Ontogeny of performance in vertebrates. Physiol Biochem Zool 79:1-6

*Higham TE, Rogers SM, Langerhans RB, Jamniczky HA (2016) Speciation through the lens of biomechanics: locomotion, prey capture and reproductive isolation. Proc R Soc B 283:20161294

Hildebrand M (1974) Analysis of vertebrate structure. John Wiley \& Sons, New York, NY

* Inbar M, Lev-Yadun S (2005) Conspicuous and aposematic spines in the animal kingdom. Naturwissenschaften 92: 170-172

Kamezaki N, Matsui M (1997) Allometry in the loggerhead turtle, Caretta caretta. Chelonian Conserv Biol 2:421-425

* Laundré JW, Hernández L, Altendorf KB (2001) Wolves, elk and bison: reestablishing the 'landscape of fear' in Yellowstone National Park, USA. Can J Zool 79:1401-1409

K Lima SL, Dill LM (1990) Behavioral decisions made under the risk of predation: a review and prospectus. Can J Zool 68:619-640

*McCoy MW, Bolker BM, Warkentin KM, Vonesh JR (2011) Predicting predation through prey ontogeny using size dependent functional response models. Am Nat 177: 752-766

Moore TY, Biewener AA (2015) Outrun or outmaneuver: predator-prey interactions as a model system for integrating biomechanical studies in a broader ecological and evolutionary context. Integr Comp Biol 55:1188-1197 
Morgan SG (1989) Adaptive significance of spination in estuarine crab zoeae. Ecology 70:464-482

Mott CM, Salmon M (2011) Sun compass orientation by juvenile green sea turtles (Chelonia mydas). Chelonian Conserv Biol 10:73-81

Nakazawa T (2017) Individual interaction data are required in community ecology: a conceptual review of the predator-prey mass ratio and more. Ecol Res 32:5-12

Naro-Maciel E, Le M, FitzSimmons NN, Amato G (2008) Evolutionary relationships of marine turtles: a molecular phylogeny based on nuclear and mitochondrial genes. Mol Phylogenet Evol 49:659-662

Pate JH, Salmon M (2017) Ontogenetic niches and the development of body shape in juvenile sea turtles. Chelonian Conserv Biol 16:185-193

Pritchard PCH (2007) Evolutionary relationships, osteology, morphology, and zoogeography of ridley sea turtles. In: Plotkin PT (ed) Biology and conservation of ridley sea turtles. Johns Hopkins University Press, Baltimore, MD, p 45-58

Salmon M, Scholl J (2014) Allometric growth in juvenile marine turtles: possible role as an antipredator adaptation. Zoology 117:131-138

Salmon M, Jones TT, Horch KW (2004) Ontogeny of diving and feeding behavior in juvenile sea turtles: leatherback turtles (Dermochelys coriacea L) and green turtles (Chelonia mydas L) in the Florida Current. J Herpetol 38: 36-43

Salmon M, Hamann M, Wyneken J (2010) The development of early diving behavior by juvenile flatback sea turtles (Natator depressus). Chelonian Conserv Biol 9:8-17

Salmon M, Higgins BM, Stewart J, Wyneken J (2015) The ontogeny of morphological defenses in Kemp's ridley (Lepidochelys kempii) and loggerhead (Caretta caretta) sea turtles. J Morphol 276:929-940

Salmon M, Wyneken J, Hamann M, Whiting S (2016) Early growth and development of morphological defenses in post-hatchling flatbacks (Natator depressus) and green turtles (Chelonia mydas). Mar Freshwat Behav Physiol 49:421-435

Salmon M, Coppenrath C, Higgins BM (2018) The early ontogeny of carapace armoring in hawksbill sea turtles (Eretmochelys imbricata), with comparisons to its close

Editorial responsibility: Paolo Casale,

Pisa, Italy relatives (loggerhead, Caretta caretta; Kemp's ridley, Lepidochelys kempii). J Morphol 201:1-10

Schmidt-Nielsen K (1984) Scaling: Why is animal size so important? Cambridge University Press, Cambridge

Schmitz OJ (2017) Predator and prey functional traits: understanding the adaptive machinery driving predator-prey interactions. F1000 Res 6:1767

Schmitz OJ, Buchkowski RW, Burghardt KT, Donihue CM (2015) Functional traits and trait-mediated interactions: connecting community-level interactions with ecosystem functioning. Adv Ecol Res 52:319-344

Smith MM, Salmon M (2009) A comparison between the habitat choices made by hatchling and juvenile green turtles (Chelonia mydas) and loggerheads (Caretta caretta). Mar Turtle Newsl 126:9-13

van Buskirk J, Crowder LB (1994) Life-history variation in marine turtles. Copeia 1994:66-81

Vogel S (1983) Life in moving fluids: the physical biology of flow. Princeton University Press, Princeton, NJ

*Walker TA (1991) Juvenile flatback turtles in proximity to coastal nesting islands in the Great Barrier Reef province. J Herpetol 25:246-248

Walker TA, Parmenter CJ (1990) Absence of a pelagic phase in the life cycle of the flatback turtle, Natator depressa (Garman). J Biogeogr 17:275-278

WWebb PW (1984) Form and function in fish swimming. Sci Am 251:72-83

Werner EE, Gilliam JF (1984) The ontogenetic niche and species interactions in size-structured populations. Annu Rev Ecol Syst 15:393-425

Witherington B (2002) Ecology of neonate loggerhead turtles inhabiting lines of downwelling near a Gulf Stream front. Mar Biol 140:843-853

Witherington BE, Hirama S, Hardy R (2012) Young sea turtles of the pelagic Sargassum-dominated drift community: habitat use, population density, and threats. Mar Ecol Prog Ser 463:1-22

Wyneken J (1997) Sea turtle locomotion: mechanics, behavior, and energetics. In: Lutz PL, Musick JA (eds) The biology of sea turtles. CRC Press, Boca Raton, FL, p 165-198

Zar GH (1999) Biostatistical analysis. Princeton-Hall, Upper Saddle River, NJ

Submitted: July 16, 2018; Accepted: October 24, 2018

Proofs received from author(s): December 2, 2018 